\title{
PELABELAN L(2,1) PADA GRAF SIERPIŃSKI S(n,k)
}

\author{
Oleh: \\ Yuri Sagala ${ }^{1}$, Susiana ${ }^{2}$ \\ ${ }^{1,2}$ FMIPA, UNIMED Medan, Indonesia \\ e-mail: analisissagala@yahoo.co.id \\ e-mail: shusie19@yahoo.co.id
}

\begin{abstract}
Abstrak
Pelabelan $L(2,1)$ pada sebuah graf $G$ adalah fungsi $f$ dari himpunan verteks $V(G)$ ke himpunan semua bilangan non-negatif sehingga $|f(u)-f(w)| \geq 2$ jika $d(u, w)=1$ dan $\mid f(u)$ $|f(w)| \geq 1$ jika $d(u, w)=2$. Bilangan pelabelan $L(2,1)$ dari sebuah graf $G$ adalah bulangan $k$ terkecil sehingga $G$ memiliki pelabelan $L(2,1)$ dengan $\max \{f(v): v \in V(G)\}=k$. Graf Sierpiński merupakan salah satu bentuk graf khusus perluasan dari graf lengkap. Pada penelitian ini ditunjukkan pelabelan pada graf Sierpiński dengan menggunakan algoritma Chang-Kuo dan diperoleh nilai $L(2,1)\{S(n, 2)\}=4$ dan nilai $L(2,1)\{S(n, 3)\}=6$ untuk $n \geq 2$, dengan $L(2,1)\{G\}$ adalah bilangan maksimum terkecil pelabelan $L(2,1)$ dari sebuah graf $G$.
\end{abstract}

Kata kunci: Pelabelan L(2,1), graf Sierpiński, nilai $L(2,1)\{S(n, k)\}$

\section{Abstract}

An $L(2,1)$-labeling of a graph $G$ is a function $f$ from the vertex set $V(G)$ to the set of all nonnegative integers such that $f(u)-f(w) \mid \geq 2$ if $d(u, w)=1$ and $|f(u)-| f(w) \mid \geq 1$ if $d(u, w)=$ 2. The $L(2,1)$-labeling number of a graph $G$ is the smallest number $k$ such that $G$ has an $L(2,1)$-labeling number with $\max \{f(v): v \in V(G)\}=k$. Sierpinski graph is one of generalization of complete graphs. In this paper, we show the $(2,1)$-labeling of Sierpinski graph by using Chang-Kuo algorithm and show that $L(2,1)\{S(n, 2)\}=4$ and nilai $L(2,1)\{S(n, 3)\}=6$ for $n \geq 2$, when $L(2,1)\{G\}$ is a smallest maximum number of $L(2,1)$ labeling of a graph $G$.

Keywords: L(2,1)-labeling, Sierpiński graph, $L(2,1)\{S(n, k)\}$-value 


\section{Pendahuluan}

Matematika adalah salah satu ilmu yang banyak memberikan alternatif dalam mempermudah menyelesaikan suatu permasalahan di segala bidang. Salah satu cabang ilmu matematika yang bermanfaat dalam kehidupan sehari-hari adalah teori graf. Teori graf merupakan salah satu bidang matematika yang diperkenalkan pertama kali oleh ahli matematika asal Swiss, Leonhard Euler pada tahun 1736. Ide besarnya muncul sebagai upaya menyelesaikan masalah jembatan Königsberg. Di Königsberg (sebelah timur Prussia, Jerman) sekarang bernama Kaliningrad terdapat sungai Pregal yang mengitari pulau Kneiphof lalu bercabang menjadi dua anak sungai tersebut.

Saat ini teori graf semakin berkembang dan menarik karena keunikan dan banyak sekali penerapannya. Keunikan teori graf adalah kesederhanaan pokok bahasan yang dipelajarinya, karena dapat disajikan sebagai titik (vertex) dan jalur (edge). Misalnya menyelesaikan permasalahan pencarian lintasan terpendek, permasalahan pengiriman surat (The Postman Problem), penentuan frekuensi pemancar radio dan lain-lain dapat diselesaikan dengan teori graf. Permasalahan seperti inilah yang dapat dimodelkan dalam bentuk graf dengan verteks-verteks pada graf berkorespondensi dengan tempat-tempat yang berbeda dan dua verteks pada graf dihubungkan dengan satu sisi atau jalur jika dan hanya jika dua tempat yang berkorespondensi dengan dua verteks tersebut dihubungkan dengan sebuah jalur. Permasalahan yang muncul pada penentuan frekuensi pemancar radio adalah menentukan frekuensi pada setiap pemancar radio sehingga jika ada dua pemancar yang berdekatan, maka pemancar tersebut diberikan frekuensi yang berbeda. Tentu saja, pemancar yang berdekatan harus menerima frekuensi dengan selisih yang cukup untuk menghindari pelayangan. Permasalahan ini bermula dari pembicaraan Fred Roberts dengan Jerrold Griggs, yang berencana menggunakan bilangan nonnegatif untuk mewakili saluran radio untuk mempelajari permasalahan penentuan saluran radio secara optimal pada pemancar pada lokasi tertentu. Hasilnya, [1] memperkenalkan pelabelan $\mathrm{L}(\mathrm{h}, \mathrm{k})$, yaitu pelabelan yang diberikan pada verteks suatu graf yang bergantung tidak hanya pada dua verteks bertetangga (berjarak satu), tetapi juga berjarak dua. Permasalahan yang lain adalah bagaimana meminimumkan rentang pelabelan pada suatu graf yang diberikan [2]. Pada penelitian ini, penulis menunjukkan pelabelan $\mathrm{L}(2,1)$ pada graf Sierpiński. Graf Sierpiński $S(n, k)$ diperluas dari $S(n, k)$ oleh [3] untuk $k \geq 3$. Motivasi untuk perluasan ini muncul dari studi topologi ruang Lipscomb, dan ditunjukkan bahwa ruang ini adalah perluasan dari segitiga Sierpiński. Kemudian, graf ini banyak dipelajari dari berbagai sudut pandang \{[4], [5], [6]). Graf Sierpiński $S(n, k)$ diperluas dengan proses: $S(1, k)$ 
isomorfik dengan graf lengkap $k$ verteks $\left(K_{k}\right) . S(n+1, k)$ dibuat dari $S(n, k)$ dengan menggandakan $n$ kali graf $S(n, k)$ dan menambahkan tepatnya satu jalur pada setiap hasil penggandaannya. Dengan demikian, penulis merumuskan judul, yakni: Pelabelan L(2,1) pada graf Sierpiński S(n,k).

Permasalahan pada tulisan ini adalah : (a) Untuk setiap $\mathrm{n}$ dan $\mathrm{k}$ yang diberikan pada sebuah graf Sierpiński S(n,k), bagaimana memberikan labelnya, (b) Berapakah nilai maksimum terkecil pelabelan L $(2,1)$ pada graf Sierpiński? Adapun batasan masalah dalam penelitian ini adalah menentukan pelabelan L $(2,1)$ pada graf Sierpiński dengan $n \geq$ 2 dan $\mathrm{k}=2,3$

\section{Graf Sierpiński}

Definisi 2.1 [6]. Graf Sierpiński $S(n, k)$ memiliki himpunan verteks $\{1,2,3 \ldots, k\}^{n}$. Dua verteks berbeda $u=\left\{i_{1}, i_{2, \ldots}, i_{n}\right\}$ dan $v=\left\{j_{1}, j_{2}, \ldots, j_{n}\right\}$ bertetangga jika dan hanya jika terdapat $h \in\{1,2, \ldots, n\}$ sehingga

- $i_{t}=j_{t}$ untuk $t=1,2,3, \ldots, h-1$;

- $i_{h} \neq j_{h} ; d a n$

- $i_{t}=j_{h}$ dan $i_{h}=j_{t}$ untuk $t=h+1, \ldots, n$

Contoh graf Sierpiński dapat dilihat pada Gambar 1 dan Gambar 2

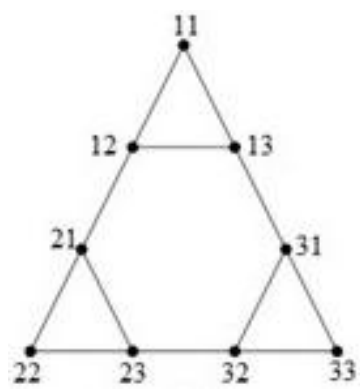

Gambar 1 Graf Sierpiński S(2,3) 


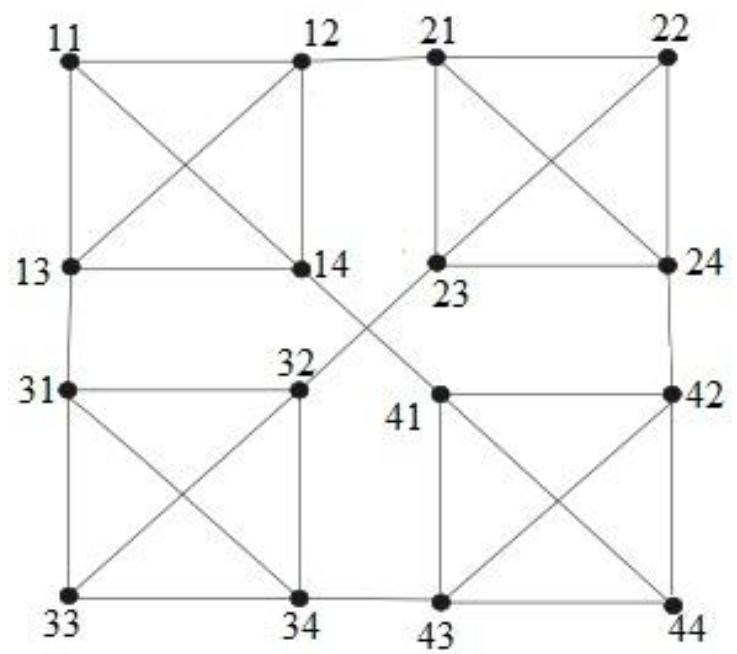

Gambar 2 Graf Sierpiński S(2,4)

\section{Pelabelan $L(2,1)$}

Definisi 3.1 [7].

Pelabelan $L(2,1)$ pada sebuah graf $G$ adalah fungsi $f$ dari himpunan verteks $V(G)$ ke himpunan semua bilangan non-negatif sehingga $|f(u)-f(w)| \geq 2$ jika $d(u, w)=1$ dan $\mid f(u)$ $|f(w)| \geq 1$ jika $d(u, w)=2$.

Definisi 3.1 mensyaratkan label yang diberikan untuk dua verteks yang berjarak 1 dan berjarak 2. Artinya untuk dua verteks yang berjarak 3 boleh diberikan label yang sama. Permasalahan yang lain untuk pelabelan $\mathrm{L}(2,1)$ adalah rentang pelabelan (span). Rentang pelabelan $\mathrm{f}$ adalah nilai maksimum $|f(u)-| f(w) \mid$ pada setiap verteks u dan w di G.yang dinotasikan dengan $\lambda_{2,1}(f)$, atau

$$
\lambda_{2,1}(\mathrm{f})=\max \{\mid f(u)-f(w): u, w \in V(G)\}
$$

Sehingga bilangan $\lambda_{2,1}$ atau rentang pelabelan $\mathrm{L}(2,1)$ dari graf $\mathrm{G}$ adalah

$$
\lambda_{2,1}(\mathrm{G})=\left\{\min \lambda_{2,1}(\mathrm{f})\right\}
$$

dengan nilai minimum diambil dari semua bilangan $f$ pada pelabelan $\mathrm{L}(2,1)$ di G. Pada konteks ini, $\mathrm{L}(2,1)\{\mathrm{G}\}$ adalah bilangan positif $\mathrm{k}$ yang terkecil untuk bilangan pelabelan $\mathrm{L}(2,1)$ dengan fungsi $\mathrm{f}: \mathrm{V}(\mathrm{G}) \rightarrow\{0,1,2, \ldots, \mathrm{k}\}$. Biasanya 0 diambil sebagai bilangan terkecil pada pelabelan $\mathrm{L}(2,1)$ pada graf $\mathrm{G}$, akibatnya adalah $\mathrm{L}(2,1)\{\mathrm{G}\}$ adalah bilangan maksimum terkecil yang dapat muncul pada pelabelan L(2,1) pada graf G, [7].

Proposisi 3.1 [8] Misalkan $P_{n}$ adalah graf yang berupa lintasan dengan $n$ verteks, terdapat pola perulangan pelabelan $L(2,1)$ pada graf $P_{n}$ dan $L(2,1)\left\{P_{n}\right\}=4$ dengan $n \geq$ 5.

Bukti. Akan ditunjukkan pelabelan $L(2,1)$ pada graf $P_{5}$.

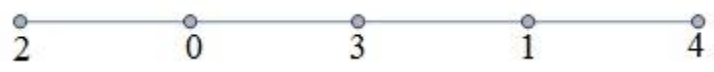


Gambar 3 Pelabelan $\mathrm{L}(2,1)$ untuk graf $\mathrm{P}_{5}$

Gambar 3 menunjukkan pelabelan graf $\mathrm{P}_{5}$. Apabila pada graf tersebut ditambahkan satu verteks, maka verteks berlabel 2 atau berlabel 6 dapat diletakkan adjacent dengan verteks berlabel 4, sebab memiliki selisih minimum 2, dan memiliki selisih minimum 1 dengan verteks yang berjarak 2 dengannya, yaitu verteks berlabel 1, sebagaimana ketentuan pelabelan L(2,1). Apabila verteks berlabel 6 diletakkan adjacent dengan verteks berlabel 4, maka nilai maksimum pelabelan $\mathrm{L}(2,1)$ pada graf $P_{n}$ dengan $\mathrm{n} \geq 5$ adalah 6 , tetapi apabila verteks berlabel 2 diletakkan, maka nilai maksimum pelabelannya adalah 4 . Karena $2<6$, maka dipilih 2 sebagai label verteks yang ditambahkan, sehingga nilai maksimum pelabelannya adalah 4. Apabila ditambahkan lagi verteks-verteks pada graf tersebut, maka graf tersebut berlabel $2,0,3,1,4,2,0,3,1,4, \ldots$ dan label tersebut selalu berulang. Dari pola berulangan verteks tersebut, 4 adalah nilai pelabelan maksimum terkecil pada graf $P_{n}$ dengan $n \geq 5$, sehingga $L(2,1)\left\{P_{n}\right\}=4$.

Q.E.D

Lemma 3.1 [4]. Pada graf lengkap $K_{k}, \mathrm{~L}(2,1)\left\{\mathrm{K}_{\mathrm{k}}\right\}=2 \mathrm{k}-2$

Bukti. Graf lengkap memiliki jalur yang menghubungkan setiap dua verteks yang berbeda. Jika salah satu verteks diberi labe 0 , maka verteks yang lain dapat diberi label 2,4,6, dan seterusnya. Bilangan ganjil tidak dapat diberikan sebab akan adjacent dengan verteks yang lainnya. Sehingga himpunan label yang dapat diberikan adalah $\{0,2,4, . ., 2 k$ 2\}. Q.E.D

\section{Metode Penelitian}

Jenis penelitian dalam tulisan ini adalah studi literatur, yaitu metode yang penelitiannya dilakukan dengan studi kepustakaan dan mempelajari karya-karya ilmiah yang disajikan dalam bentuk buku, teks, dan dokumen yang berkaitan dengan topik pembahasan. Penelitian ini akan dilakukan di Perpustakaan Universitas Negeri Medan danpenelitian ini akan berlangsung selama kurang lebih 1 bulan.

\section{Hasil Penelitian Dan Pembahasan}

\section{A. Algoritma Pelabelan L(2,1)}

Definisi 4.1 [9]. Subhimpunan $X$ dari $V(G)$ disebut i-himpunan stabil (atau i-himpunan bebas) jika jarak antara dua verteks di X lebih besar daripada i. Sebuah 2-subhimpunan stabil maksimal $X$ dari himpunan $Y$ adalah 2-subhimpunan stabil dari $Y$, sehingga $X$ bukan bukan subhimpunan sejati dari 2-subhimpunan stabil dari X. 
Menurut Chang dan Kuo dalam [9], algoritma pelabelan L(2,1) adalah sebagai berikut.

\section{Algoritma 4.1 (Algoritma Chang-Kuo).}

Masukan: $\mathrm{Graf} \mathrm{G}=(\mathrm{V}, \mathrm{E})$

Keluaran: Nilai pelabelan maksimum $k$.

Gagasan: Menemukan 2-himpunan stabil maksimal pada setiap langkahnya dari verteks yang belum berlabel yang berjarak paling sedikit 2 dari verteks yang sudah dilabeli pada langkah sebelumnya. Kemudian melabel semua verteks pada 2- himpunan stabil dengan indeks $i$ pada langkah umum. Indeks $i$ dimulai dari 0 dan

bertambah 1 pada setiap langkahnya. Label maksimum $k$ aalah nilai akhir dari $i$.

Inisialisasi: $X_{-1}=\phi ; V=V(G) ; i=0$

Iterasi:

1. Menentukan $Y_{i}$ dan $X_{i}$

- $Y_{i}=\left\{x \in V: x\right.$ belum berlabel dan $d(x, y) \geq 2$ untuk $\left.y \in X_{i-1}\right\}$

- $X_{i}$ adalah 2-subhimpunan stabil maksimal dari $Y_{i}$

- $\operatorname{Jika} Y_{i}=\phi$, maka $X_{i}=\varnothing$

2. Melabeli semua verteks di $X_{i}$ dengan $i$

3. $V \leftarrow И X_{i}$

4. Jika $V \neq \varnothing$, maka $i \leftarrow i+1$, kemudian mengulangi kembali langkah 1 .

5. Mengulangi i tertentu sebanyak $k$, yaitu label makimumnya. Berhenti.

\section{B. Pelabelan L(2,1) pada Graf Sierpiński}

- Untuk k = 2

Graf $S(n, 2)$ adalah graf yang berbentuk path yang terdiri dari $2^{\mathrm{n}}$ verteks.

$\circ \quad$ Untuk $n=2$.

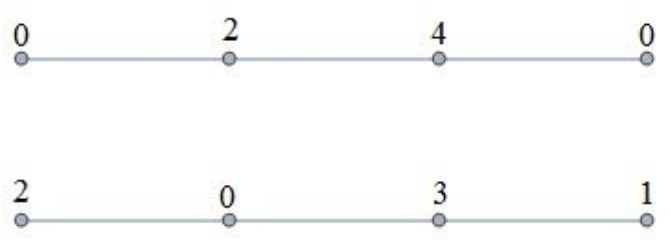

Gambar 4. Hasil Pelabelan L $(2,1)$ untuk graf $S(2,2)$

Dari kedua gambar di atas, terdapat perbedaan nilai maksimum pelabelan yang diberikan, hal ini disebabkan pengambilan verteks awalnya. Karena nilai maksimum pelabelan $L(2,1)$ diambil bilangan terkecil, yaitu 3, maka $L(2,1)\{S(2,2)\}=3$. 
- Untuk $\mathrm{n}=3$

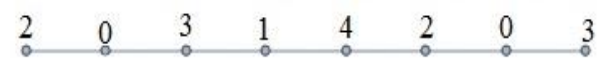

Gambar 5 Hasil Pelabelan L(2,1) untuk graf $\mathrm{S}(3,2)$

Pada Gambar 5, terlihat pola perulangan label yang diberikan pada graf $S(n, 2)$ untuk $n=$ 3. Sehingga untuk $\mathrm{n} \geq 3$ dapat dimunculkan teorema sebagai berikut.

Teorema 5.1 Untuk $n \geq 3$, nilai maksimum terkecil graf $S(n, 2)$ adalah 4.

Bukti. Dari definisi graf Sierpinski $S(n, k)$ mengakibatkan graf $S(n, 2)$ merupakan graf yang berbentuk lintasan yang terdiri dari $2^{\mathrm{n}}$ verteks. Karena $\mathrm{S}(\mathrm{n}, 2)$ merupakan graf yang berbentuk lintasan, maka berdasarkan proposisi 3.1, maka $\mathrm{L}(2,1)\{\mathrm{S}(\mathrm{n}, 2)\}=4$ untuk $\mathrm{n} \geq 3$. Q.E.D

- $\quad$ Untuk k = 3

○ Untuk $\mathrm{n}=2$

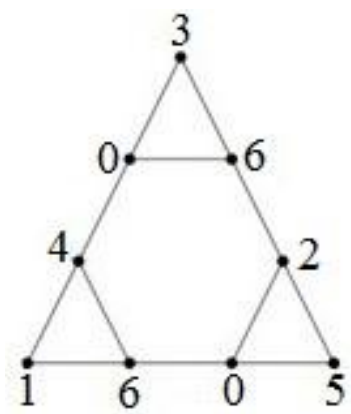

Gambar 6 Hasil Pelabelan L(2,1) untuk graf $S(2,3)$

○ Untuk $\mathrm{n}=3$ 


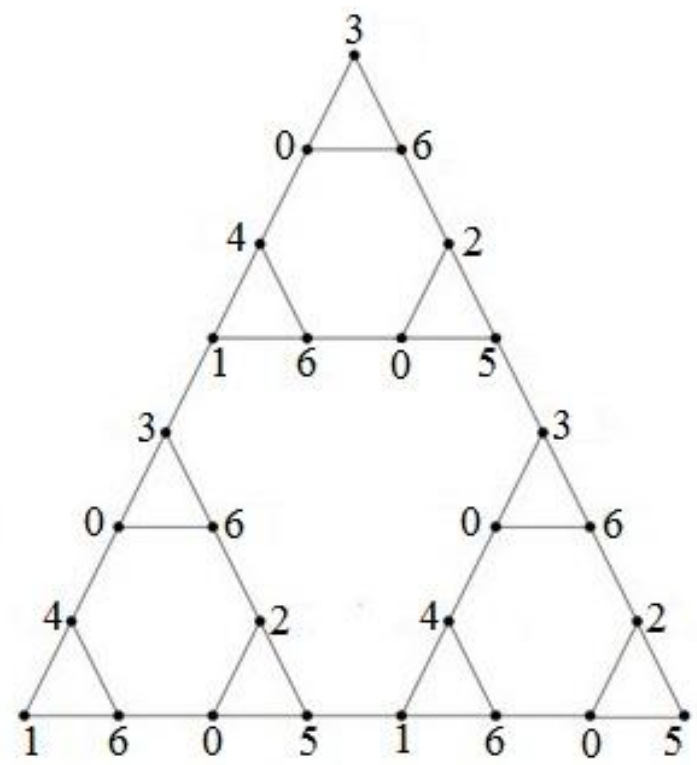

Gambar 7 Hasil Pelabelan L(2,1) untuk graf S(3,3)

Dari Gambar 6 dan Gambar 7 terlihat ada pola berulang pada graf S(n,3) dengan $\mathrm{L}(2,1)\{\mathrm{S}(\mathrm{n}, 3)\}=6$, sehingga dapat dimunculkan teorema sebagai berikut:

Teorema 5.2 Untuk $n \geq 3$, terdapat pola berulang pelabelan $L(2,1)$ pada graf $S(n, 3)$ dan $L(2,1)\{S(n, 3)\}=6$.

Bukti. Akan ditunjukkan terdapat pola berulang pelabelan $\mathrm{L}(2,1)$ pada graf Sierpiński pada graf $S(3,3)$. Agar terdapat pola berulang, verteks ekstrim pada $S(2,3)$ harus memiliki label dengan selisih minimum 2, sebab untuk nilai n yang lebih besar, verteks ekstrim tersebut akan saling bertetangga dan verteks-verteks yang bertetangga dengan verteks ekstrim harus memiliki selisih satu dengan verteks ekstrim lainnya, sebab untuk nilai $n$ yang lebih besar, verteks tersebut akan berjarak dua juga dengan verteks ekstrim lainnya. Pada Gambar 6 dan Gambar 7 terlihat bahwa verteks ekstrim memiliki labbel 3,1, dan 5, artinya verteks tersebut dapat terhubung jalur untuk nilai $\mathrm{n}$ yang lebih besar, dan verteks yang adjacent dengan verteks ekstrim memiliki selisih minimum 1 dengan verteks ekstrim lainnya. Dari nilai pelabelan verteks tersebut, 6 adalah bilangan terbesarnya, sehingga $\mathrm{L}(2,1)\{\mathrm{S}(\mathrm{n}, 3)\}=6$.

Q.E.D

\section{Penutup}

\section{A. Kesimpulan}

Nilai maksimum terkecil pelabelan $\mathrm{L}(2,1)$ adalah sebagai berikut:

a. Nilai maksimum pelabelan $\mathrm{L}(2,1)$ pada graf Sierpiński $\mathrm{S}(2,2)$ atau $\mathrm{L}(2,1)\{\mathrm{S}(2,2)\}$ adalah 3 . 
b. Nilai maksimum pelabelan $\mathrm{L}(2,1)$ pada graf Sierpiński $\mathrm{S}(\mathrm{n}, 2)$ atau $\mathrm{L}(2,1)\{\mathrm{S}(\mathrm{n}, 2)\}$ dengan $\mathrm{n} \geq 3$ adalah 4 .

c. Nilai maksimum pelabelan $\mathrm{L}(2,1)$ pada graf Sierpiński $\mathrm{S}(\mathrm{n}, 3)$ atau $\mathrm{L}(2,1)\{\mathrm{S}(\mathrm{n}, 3)\}$ dengan $\mathrm{n} \geq 2$ adalah 6 .

\section{B. Saran}

Jika pembaca tertarik melanjutkan penelitian ini, penulis menyarankan hal-hal berikut:

a. Algoritma Chang-Kuo untuk pelabelan $\mathrm{L}(2,1)$ memiliki kelemahan dalam pemilihan verteks. Algoritma ini hanya mempertimbangkan jarak antara kedua verteks yang akan diberi label. Penulis menyarankan perlu adanya algoritma pelabelan $\mathrm{L}(2,1)$ yang tidak hanya mempertimbangkan jarak antara kedua verteks.

b. Menyelidiki adanya pola pengulangan label pada graf Sierpiński $S(n, k)$ untuk $k \geq$ 4.

c. Melakukan pelabelan L(2,1) pada graf lainnya.

\section{DAFTAR PUSTAKA}

[1] Griggs, J., dan Yeh, R., (1992): Labeling graphs with a condition at distance two, SIAM J. Disc. Math, 5(4), 586-595.

[2] Klavžar, S., dan Milutinovič, U., (1997): Graph S(n,k) and a Variant of The Tower of Hanoi Problem, Czechoslovak Math J., 47(122), 95-104

[3] Hale, W., (1980): Frequency assignment: theory and application, Proc IEEE, 68, 1479-1514.

[4] Fu, H., dan Xie, D., (2010): Equitable L(2,1)-labelings of Sierpiński graphs, Austalasian Journal of Combinatorics, 46, 147-156.

[5] Gravier, S., Kovše, M., dan Parreau, A., (2009): Generalized Sierpiński graphs, ANR IDEA.

[6] Gravier, S., Klavžar S., dan Mollard, M., (2005): Codes and L(2,1)-labelings in Sierpiński graphs, Taiwanese Journal of Mathematics, 9(4), 671-681.

[7] Chartrand, G., dan Zhang, P., (2009): Chromatic Graph Theory, CRC Press, USA. 
KARISMATIKA

p-ISSN : $2443-0366$

VOL. 3 NO. 2 AGUSTUS 2017

[8] Lum, A., (2007): Upper Bound on L(2,1)-labeling Number of Graphs with Maximum Degree $\Delta$.

[9] Shao, Z., Yeh R., dan Zhang D., (2008): The L(2,1)-labeling on graphs and the frequency assignment problem, Elsevier, 21, 37-41

\section{${ }^{1}$ Yuri C Sagala}

${ }^{2}$ Susiana 